\title{
EDITORIAL
}

\section{Building communities of respect in the intensive care unit}

\author{
Samuel M. Brown ${ }^{1 *}$, Daniel Talmor ${ }^{2}$ and Michael D. Howell ${ }^{3}$
}

๑ 2018 Springer-Verlag GmbH Germany, part of Springer Nature and ESICM

"R-E-S-P-E-C-T", calls out Aretha Franklin in her legendary 1967 soul anthem, you "don't know what it means to me". As we have spent several years considering the question of respect as it applies in the intensive care unit (ICU), we've come to appreciate both the power of Franklin's song and the conundrum posed by the reality that we don't know as much about respect as we think.

Many groups have been whittling away at that ignorance. We and collaborators have proposed a conceptual framework and research program $[1,2]$ and reported the results of a modified Delphi consensus process to provide guidance to health systems attempting to improve the practice of respect in healthcare [3]. Some investigators have implemented systems for monitoring and responding to disrespect events [4]. Others have documented the ubiquity of disrespectful ICU cultures across the world $[5,6]$. We have also explored unintended consequences and tragic trade-offs in respect [7]. To facilitate discussion, we have adopted a practical definition (admitting considerable complexity in the philosophical debates underlying questions about human dignity [8]) for the key terms, respect and dignity: "dignity represents the inherent worth of all human beings, and respect represents the actions that appropriately honor and acknowledge such dignity" [2].

The importance of respect for all participants in the ICU is clear $[2,4,7,9]$. In this commentary, we focus on the interdependence of respect among participants in the healthcare system, sketching out the ecosystems-a biological metaphor which draws attention to the many individuals, systems, infrastructures, constituencies, and

\footnotetext{
*Correspondence: samuel.brown@imail.org

${ }^{1}$ Center for Humanizing Critical Care, Intermountain Medical Center and Department of Internal Medicine, University of Utah School of Medicine, Murray, UT, USA

Full author information is available at the end of the article
}

hierarchies within which medical care occurs-within which respect unfolds. It is important to see respect and dignity as more than a patient advocacy question, however important such advocacy is. In a word, this is not a story about improving experience scores or achieving "customer satisfaction". Instead, it is the old, admittedly nebulous question of what it means to be human, how we might improve contemporary and future healthcare systems, and how all of this applies to the ICU.

The ecosystem of respect is profoundly vulnerable to the function of healthcare's systems of care. Poorly functioning systems can create tragedy for patients and clinicians alike. We note with sadness for all involved the recent case of a pediatrics trainee (Dr. Hadiza BawaGarba) in the UK who was convicted of gross negligence manslaughter after missing progressive (ultimately fatal) sepsis and failing to prevent the mother administering an outpatient anti-hypertensive medication to a 6-year-old boy $[10,11]$. The errors occurred in a systemically terrible situation-with information technology failures, lack of supervision, and a crushing census. Essentially all physician observers have responded in horror at the failure of systemic accountability in this case. For many European clinicians, the Bawa-Garba case is emblematic of grave, systemic disrespect for clinicians within increasingly dysfunctional institutions. Respect for all participants within healthcare systems, including clinicians, helps create both a humane working environment and the best possible care for patients.

We emphasize two orienting points. First, respect (from Latin meaning to look again) and dignity (from Latin indicating worth or merit) call us to recognize that the people we encounter are worth seeing [7]. Second, respect is closely tied to humanization-the belief that the other person has a perspective on the world that matters [12].

\section{Springer}


Respect is about how human beings interact with each other. It's fundamentally a story about the integrity of a healthy community. That healthy community stands at the basis of respect. We draw attention to the members of the community within the ICU, with an eye toward helping to understand how they may show respect to each other. We also acknowledge that the family and friends of clinicians have a role to play in this broader community.

One of the difficult aspects about modern intensive care is the sense of depersonalization, alienation, and separation from prior points of community support. This is true for patients and families, for whom the ability to work may be permanently interrupted by critical illness and its aftermath. But it is also true for clinicians. Today, work has become central to personal identity. Clinicians often derive their identity from professional status and the workplace environment. A key change-still in evolution-is that physicians have historically been at the pinnacle of the medical hierarchy, but today physicians increasingly feel displaced from that position by administrators, executives, and regulators. This displacement of physicians creates new risks for disrespect. As non-clinicians concentrate more power in themselves, it will be incumbent upon them to practice respect for clinicians and others. The call to respect remains important for physicians in their interactions with other staff, patients, and families, even as they may feel embattled in the new system.

Systems of mutual respect will require teamwork and an ongoing commitment to the collaboration necessary to support that teamwork. The design of work teams and contexts will have an outsized influence on the practice of respect in the ICU, and these designs will need to support clinicians, patients, and families as well. We cannot build functional teams if key team members are physically restricted on a routine basis from the bedside in the ICU $[13,14]$. Teams built on mutual respect are necessary and should encompass managers, clinicians, patients, and families.

We should distinguish between being respected and having one's own way. All participants will have to make compromises to make systems work. Not all of us will be perfectly content with every choice that is made. That give and take is central to community. But the point is that there must be a give and take that reasonably acknowledges the personhood of all participants. We also will need to be cautious about the risks of unintended consequences with any specific approaches we take to improving the practice of respect [15-19].

We know that when physicians treat nurses poorly, everyone is worse off, and vice versa. We know that when clinicians treat patients or families poorly, everyone is worse off, and vice versa. Rudeness and dehumanization are contagious, self-propagating beasts [20-25]. Here we draw attention to the role of managers and regulators too, who must also heed the call to respect or risk negatively affecting patient safety and quality in spite of the best intentions. Even when we disagree, we can do so respectfully. We must not wait for others to practice respect before we do so ourselves.

We are, as the old saying goes, all in this together. It's time for us to acknowledge that fact of interdependence, across the spectrum of society and healthcare systems. Therein lies the path to mutual respect.

\section{Author details \\ ${ }^{1}$ Center for Humanizing Critical Care, Intermountain Medical Center and Department of Internal Medicine, University of Utah School of Medicine, Murray, UT, USA. ${ }^{2}$ Department of Anesthesia, Critical Care and Pain Medicine, Beth Israel Deaconess Medical Center and Harvard Medical School, Boston, MA, USA. ${ }^{3}$ Google Research, Google Inc., Mountain View, CA, USA.}

Received: 19 April 2018 Accepted: 1 June 2018 Published online: 30 June 2018

References

1. Brown SM, Rozenblum R, Aboumatar H, Fagan MB, Milic M, Lee BS, Turner K, Frosch DL (2015) Defining patient and family engagement in the intensive care unit. Am J Respir Crit Care Med 191:358-360

2. Brown SM, Azoulay E, Benoit D, Butler TP, Folcarelli P, Geller G, Rozenblum R, Sands K, Sokol-Hessner L, Talmor D, Turner K, Howell MD (2018) The practice of respect in the intensive care unit. Am J Respir Crit Care Med 197(11):1389-95

3. Sokol-Hessner L, Folcarelli P, Annas C, Brown SM, Fernandez L, Roche SD, Sarnoff Lee B, Sands K (2018) A roadmap for advancing the practice of respect in health care: the results of an interdisciplinary modified delphi consensus study. Jt Comm J Qual Patient Saf (2018 June 13, Epub ahead of print)

4. Sokol-Hessner L, Folcarelli PH, Sands KE (2015) Emotional harm from disrespect: the neglected preventable harm. BMJ Qual Saf 24:550-553

5. Van den Bulcke B, Piers R, Jensen HI, Malmgren J, Metaxa V, Reyners AK, Darmon M, Rusinova K, Talmor D, Meert AP, Cancelliere L, Zubek L, Maia P, Michalsen A, Decruyenaere J, Kompanje EJO, Azoulay E, Meganck R, Van de Sompel A, Vansteelandt S, Vlerick P, Vanheule S, Benoit DD (2018) Ethical decision-making climate in the ICU: theoretical framework and validation of a self-assessment tool. BMJ Qual Saf (2018 Feb 23, Epub ahead of print)

6. Benoit DD, Jensen HI, Malmgren J, Metaxa V, Reyners AK, Darmon M, Rusinova K, Talmor D, Meert AP, Cancelliere L, Zubek L, Maia P, Michalsen A, Vanheule S, Kompanje EJO, Decruyenaere J, Vandenberghe S, Vansteelandt S, Gadeyne B, Van den Bulcke B, Azoulay E, Piers RD (2018) Outcome in patients perceived as receiving excessive care across different ethical climates: a prospective study in 68 intensive care units in Europe and the USA. Intensive Care Med (2018):1-11

7. Brown SM, Wilson ME, Benda C, Negin H, Hopkins RO (2018) Humanizing intensive care: questions, balance, and tragic tradeoffs. In: Netzer G (ed) Management of family ICU syndrome: improving outcomes in the ICU. Springer, New York (in press)

8. Waldron J (2017) One another's equals: the basis of human equality. Harvard University Press, Cambridge

9. Brown SM (2016) Through the valley of shadows: living wills, intensive care, and making medicine human. Oxford University Press, New York

10. Ross N (2018) Letter to the GMC chair regarding Hadiza Bawa-Garba. BMJ $360: k 195$

11. Dyer C (2017) GMC to push for erasure of paediatrician convicted of manslaughter. BMJ 359:j5223 
12. Brown SM, Beesley SJ, Hopkins RO (2016) Humanizing intensive care: theory, evidence, and possibilities. In: Vincent JL (ed) Annual update in intensive care and emergency medicine 2016. Springer, Switzerland, pp 405-420

13. Brown SM (2015) We still lack patient centered visitation in intensive care units. BMJ 350:h792

14. Beesley SJ, Hopkins RO, Francis L, Chapman D, Johnson J, Johnson N, Brown SM (2016) Let them in: family presence during intensive care unit procedures. Ann Am Thorac Soc 13:1155-1159

15. Baker DW, Einstadter D, Thomas CL, Husak SS, Gordon NH, Cebul RD (2002) Mortality trends during a program that publicly reported hospital performance. Med Care 40:879-890

16. Frieden TR, Houry D (2016) Reducing the risks of relief-the CDC opioidprescribing guideline. N Engl J Med 374:1501-1504

17. Gupta A, Allen LA, Bhatt DL, Cox M, DeVore AD, Heidenreich PA, Hernandez AF, Peterson ED, Matsouaka RA, Yancy CW, Fonarow GC (2017) Association of the hospital readmissions reduction program implementation with readmission and mortality outcomes in heart failure. JAMA cardiol 3(1):44-53

18. Gilman M, Hockenberry JM, Adams EK, Milstein AS, Wilson IB, Becker ER (2015) The financial effect of value-based purchasing and the hospital readmissions reduction program on safety-net hospitals in 2014: a cohort study. Ann Intern Med 163:427-436
19. Joynt KE, Jha AK (2013) Characteristics of hospitals receiving penalties under the hospital readmissions reduction program. JAMA 309:342-343

20. Riskin A, Erez A, Foulk TA, Kugelman A, Gover A, Shoris I, Riskin KS, Bamberger PA (2015) The impact of rudeness on medical team performance: a randomized trial. Pediatrics 136:487-495

21. Riskin A, Erez A, FoulkTA, Riskin-Geuz KS, Ziv A, Sela R, Pessach-Gelblum L, Bamberger PA (2017) Rudeness and medical team performance. Pediatrics 139(2):e20162305

22. FoulkT, Woolum A, Erez A (2016) Catching rudeness is like catching a cold: the contagion effects of low-intensity negative behaviors. J App Psychol 101:50-67

23. Woolum A, Foulk T, Lanaj K, Erez A (2017) Rude color glasses: the contaminating effects of witnessed morning rudeness on perceptions and behaviors throughout the workday. J Appl Psychol 102:1658-1672

24. Langer EJ, Rodin J (1976) The effects of choice and enhanced personal responsibility for the aged: a field experiment in an institutional setting. J Personal Soc Psychol 34:191-198

25. Beach MC, Sugarman J, Johnson RL, Arbelaez JJ, Duggan PS, Cooper LA (2005) Do patients treated with dignity report higher satisfaction, adherence, and receipt of preventive care? Ann Fam Med 3:331-338 